\title{
Comparative study of structural and optical properties of zirconium-doped indium oxide synthesized by solid state reactions and sol-gel technique
}

\author{
Liliana BIZO ${ }^{1, a}$, Klara MAGYARI ${ }^{2, b}$, Julieta Daniela CHELARU ${ }^{1, c}$, Ovidiu NEMEŞ, \\ ${ }^{1}$ Universitatea Babeş-Bolyai, Faculty of Chemistry and Chemical Engineering, Department of \\ Chemical Engineering, 11 Arany Janos Street, RO-400028, Cluj-Napoca, Romania \\ ${ }^{2}$ Universitatea Babeş-Bolyai, Institute for Interdisciplinary Research on Bio-Nano-Sciences, 42 \\ Treboniu Laurian Street, RO-400271, Cluj-Napoca, Romania \\ ${ }^{3}$ Technical University of Cluj-Napoca, 28 Memorandumului Street, RO-400114, Cluj-Napoca, \\ Romania \\ albizo@chem.ubbcluj.ro, bklara.magyari@ubbcluj.ro, cjdchelaru@chem.ubbcluj.ro, \\ dovidiu.nemes@sim.utcluj.ro
}

Keywords: Advanced Electronic Materials, Transparent Conducting Oxides (TCOs), ZrDoped Indium Oxide, Structural Properties, Optical Properties

\begin{abstract}
In the present work the effect of zirconium doping (1.5 at.\%) on the structural and optical properties of indium zirconium oxide was studied. Zr-doped indium oxides were prepared by using two different methods, solid state reactions and sol-gel technique. The compositions with bixbyite structure have been synthesized by two different methods, solid state reactions in air and sol-gel process. X-ray powder diffraction (XRPD) used for phases analysis confirm the validity of the cubic bixbyite-type structure of $\operatorname{In}_{2} \mathrm{O}_{3}$. The optical properties of the prepared composition were considered in terms of their diffuse reflectance spectra (DRS). The morphology of crystals was evidenced by SEM analyses and reveal agglomeration of particles with their size ranges in the micrometer domain.
\end{abstract}

\section{Introduction}

Transparent conducting oxides (TCOs) are an important class of materials which have attracted much attention in the last years due to their main properties, low resistivity and high optical transparency. The dominant TCOs are mainly zinc oxide $(\mathrm{ZnO})$, indium oxide $\left(\operatorname{In}_{2} \mathrm{O}_{3}\right)$ and tin oxide $\left(\mathrm{SnO}_{2}\right)$, as well as subsequent mixtures of these, such as well-known indium tin oxide (ITO) [1]. $\mathrm{In}_{2} \mathrm{O}_{3}$, a wide-bandgap n-type semiconductor, is widely used in various applications due to their properties including solar applications, the transparent electrodes in various optoelectronic devices, the flat panel liquid crystals displays, the barrier layers in tunnel junctions, the active layers of gas sensors or the material for ultraviolet lasers [2]. Therefore, the physical properties of the $\mathrm{In}_{2} \mathrm{O}_{3}$, like high electrical conductivity and optical transparency in the visible range, strongly depend on the preparation method. For this reason there are many investigations which are studying their properties in dependence on the synthesis methods. These methods include physical methods such as sputtering, evaporation, pulsed laser deposition, spray pyrolysis, as well as chemical methods like chemical pyrolysis, chemical vapor deposition, sol-gel, bath deposition and electroplating [3-8]. On the other hand electrical properties of $\mathrm{In}_{2} \mathrm{O}_{3}$ can be improved by doping with metallic donor impurity. For this reason the system $\mathrm{ZrO}_{2}-\mathrm{In}_{2} \mathrm{O}_{3}$ was mostly investigated [810].

Content from this work may be used under the terms of the Creative Commons Attribution 3.0 license. Any further distribution of this work must maintain attribution to the author(s) and the title of the work, journal citation and DOI. Published under license by Materials Research Forum LLC. 
In the present paper we comparatively investigated the structural evolution, optical and morphological properties of indium zirconium oxide prepared by two methods, solid state synthesis and sol-gel route.

\section{Materials and Methods} Synthesis

Two different preparation methods were employed in the synthesis of zirconium-doped indium oxide: solid state synthesis and sol-gel method.

Compositions belonging to $\mathrm{In}_{2-\mathrm{x}} \mathrm{Zr}_{\mathrm{x}} \mathrm{O}_{3}(0.025 \leq \mathrm{x} \leq 0.15)$ system with the bixbyite structure were prepared by solid state reactions from mixtures of pure $\mathrm{In}_{2} \mathrm{O}_{3}$ (Alfa Aesar 99.995\%) and $\mathrm{ZrO}_{2}$ (Alfa Aesar 99\%) at $1400{ }^{\circ} \mathrm{C}$, in air.

In the sol-gel synthesis indium (III) nitrate hydrate $\left(\mathrm{In}\left(\mathrm{NO}_{3}\right)_{2} \cdot \mathrm{xH}_{2} \mathrm{O}\right)$ was used as a precursor and zirconium (IV) chloride $\left(\mathrm{ZrCl}_{4}\right)$ as a doping source at the molar ratios required to obtain $\operatorname{In}_{2} \mathrm{O}_{3}$ doped with 1.5 at $\% \mathrm{ZrO}_{2}$. Aqueous solutions of the two salts were stirred on a warming plate at $80{ }^{\circ} \mathrm{C}$ in order to mix the solution uniformly. The sol was prepared using isopropyl alcohol as solvent and ethylene glycol or sucrose as polymerization agent. The sucrose solution was added gradually into the aqueous solutions under stirring until colloidal suspensions were obtained. The sol continuously transformed into wet gel and then dried gel under heating at $100{ }^{\circ} \mathrm{C}$ during $24 \mathrm{~h}$. The resulted dried materials were annealed at $600{ }^{\circ} \mathrm{C}$ in air for one hour to form the required $\mathrm{Zr}$ doped indium oxide. Fig. 1 presents schematic flow chart of indium zirconium oxide obtained by solid state synthesis.

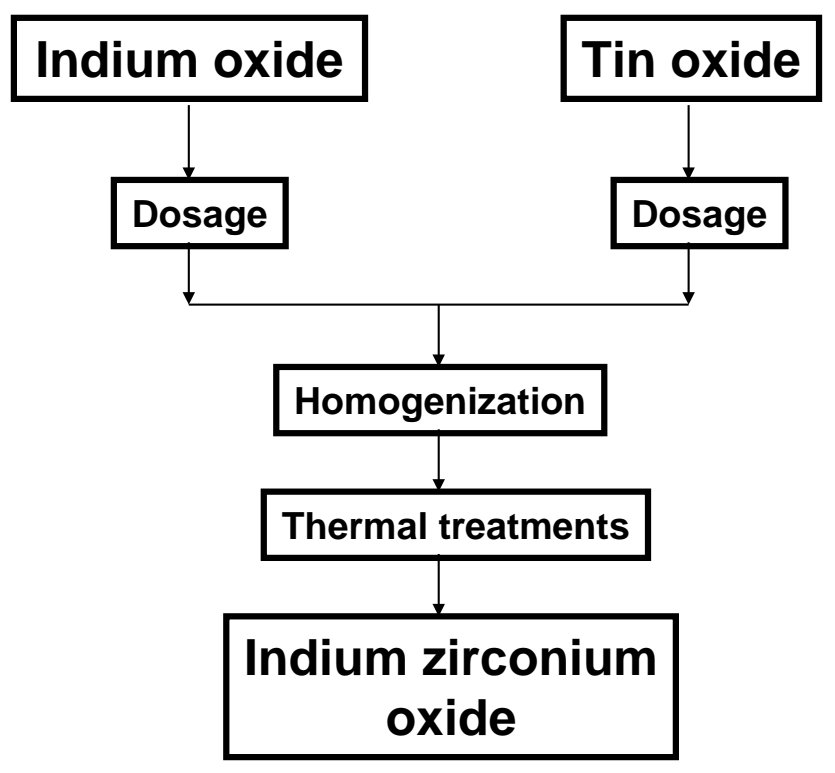

Fig. 1. Schematic flow chart of indium zirconium oxide obtained by solid state synthesis.

\section{Characterization Methods}

The X-ray powder diffraction (XRPD) data were collected in the $2 \theta=10-80^{\circ}$ angular domain with a Bruker D8 Advance diffractometer, using CuKa1 radiation (40 kV; 40 mA). 
Optical properties were investigated using a Jasco V-650 spectrophotometer (Japan) equipped with an ISV-722 Integrating Sphere. The diffusse reflectance spectra (DRS) were recorded in the range $200-800 \mathrm{~nm}$ with a scan rate of $400 \mathrm{~nm} / \mathrm{min}$.

The samples morphology was investigated using a Hitachi SU8230 Scanning Electron Microscope (SEM).

\section{Results and discussion}

\section{X-ray powder diffraction (XRPD) analysis}

The X-ray diffraction patterns of zirconium doped $\mathrm{In}_{2} \mathrm{O}_{3}$ prepared by solid state reaction with different concentrations are shown in Fig. 2. All samples showed similar XRPD patterns, indicating the high crystallinity of our bulk materials. No extra peaks are observed due to the addition of zirconium in indium oxide films which indicates the absence of an impurity phase in the prepared samples.

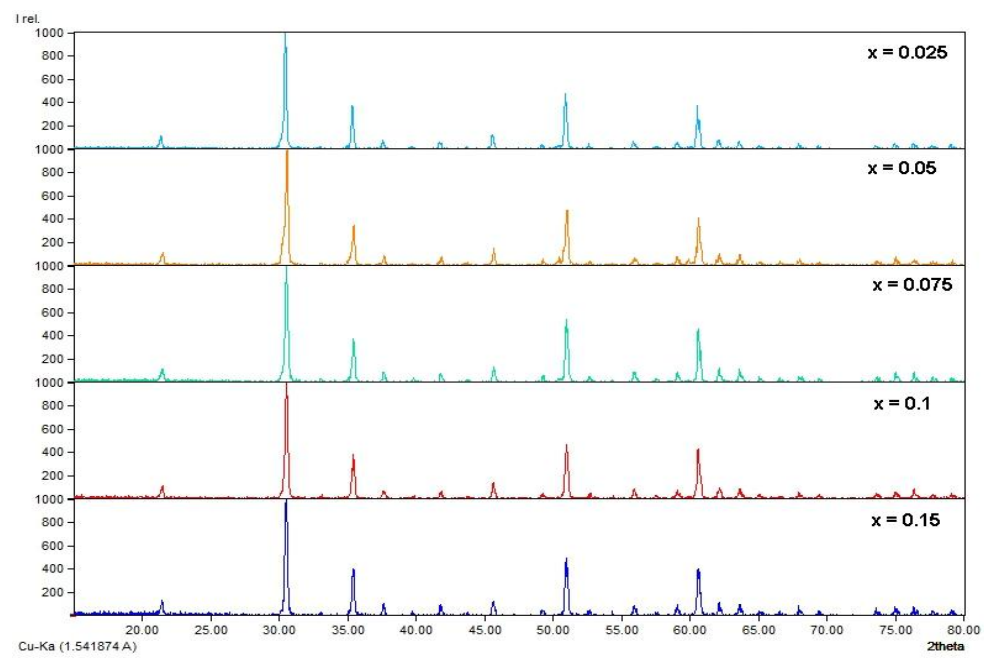

Fig. 2. XRPD patterns of $\operatorname{In}_{2-\mathrm{x}} \mathrm{Zr}_{\mathrm{x}} \mathrm{O}_{3}(0.025 \leq \mathrm{x} \leq 0.15)$ system prepared by solid state reaction.

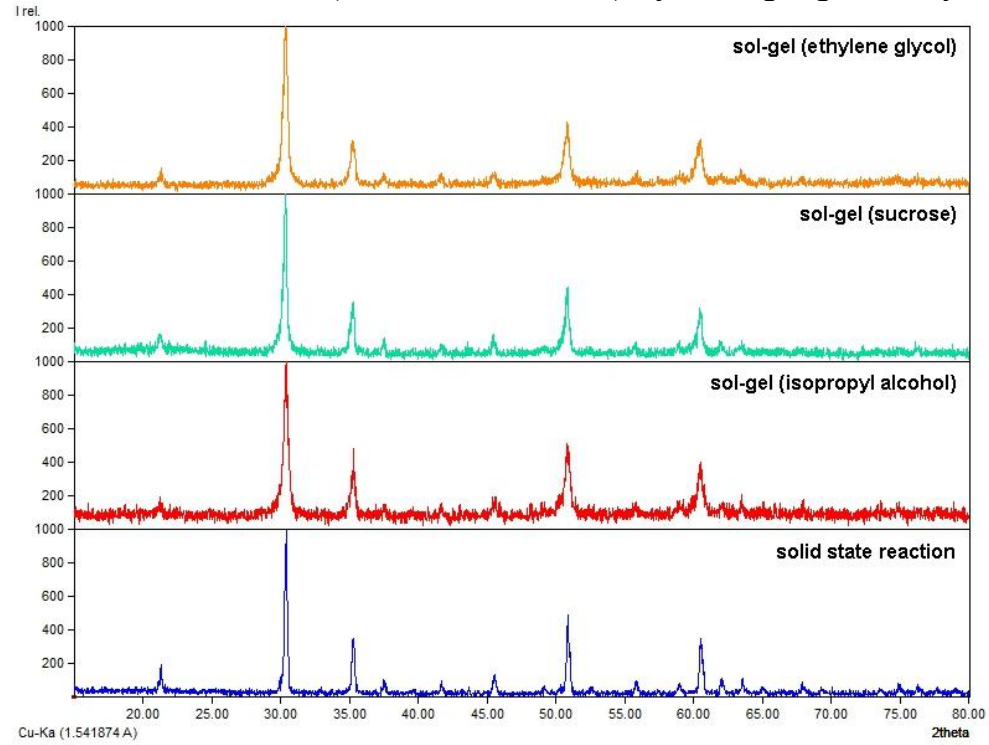

Fig. 3. XRPD patterns of $x=0.075$ composition prepared by solid state reaction (a) and sol-gel method using (b) isopropyl alcohol, (c) sucrose or (d) ethylene glycol. 
There are four prominent peaks as shown in Fig. 2, which can be indexed to the (222), (400), (440) and (622) crystal planes of the $\mathrm{In}_{2} \mathrm{O}_{3}$ cubic structure. XRPD of $\mathrm{x}=0.075$ sample prepared via sol-gel route and solid state reaction are presented comparatively in Fig. 3. From the figure, it was clear that the intensity of peaks is increased in the $\mathrm{x}=0.075$ composition prepared by solid state reaction. The increase in intensity of the peaks is due to the improvement of sample crystallinity.

\section{UV-VIS spectroscopy analysis}

Fig.4 show the difusse reflectance spectra (DRS) of zirconium doped $\operatorname{In}_{2} \mathrm{O}_{3}$ prepared by sol-gel method using isopropyl alcohol as solvent and ethylene glycol or sucrose as polymerization agent. The maximum percent reflectance around $450 \mathrm{~nm}$, observed for sample prepared using sucrose, is increasing for samples prepared using isopropyl alcohol as solvent and ethylene glycol as polymerization agent. Simultaneously, a shift of the optical bandgap to higher wavelengths occurs. The reflectance spectra of $\mathrm{x}=0.075$ composition prepared by solid state reaction and sol-gel method using sucrose are displayed comparatively in Fig. 5. One indeed observes that sol-gel preparation of zirconium doped indium oxide decreases the maximum percent reflectance around $450 \mathrm{~nm}$, by approximately $20 \%$, with respect to same composition prepared by solid state reaction.

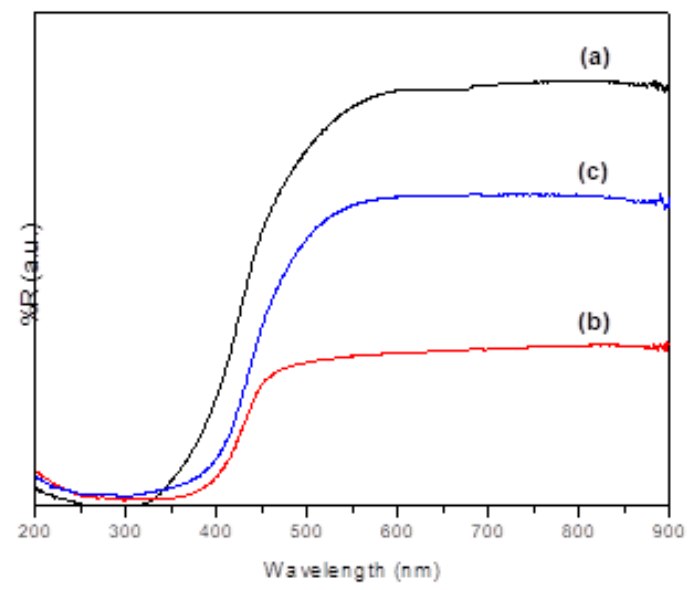

Fig. 4. Measured DRS in the compositions $x=0.075$ prepared by sol-gel method using (a) isopropyl alcohol, (b) sucrose or (c) ethylene glycol.

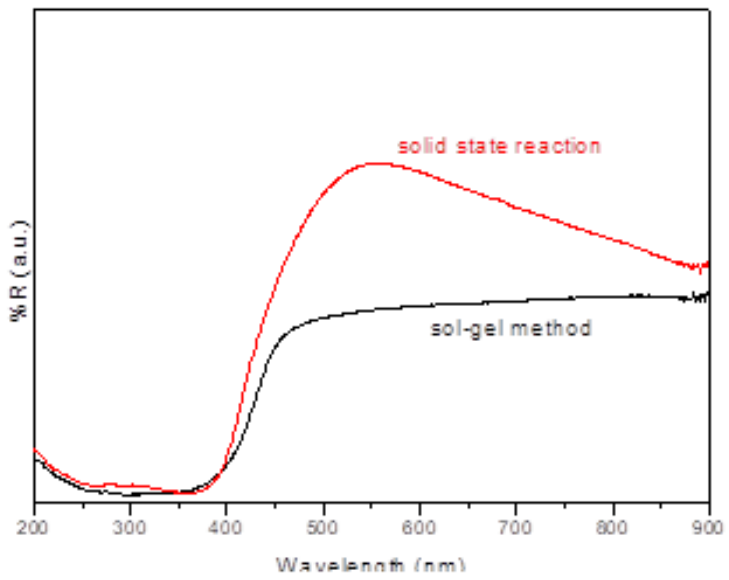

Fig. 5. Measured DRS in the composition $x=0.075$ prepared by solid state reactions (a) and sol-gel method using sucrose (b). 


\section{SEM microscopy analysis}

Scanning electron microscopy (SEM) was used to study the particle morphology of the studied samples. SEM images of the samples recorded for $\mathrm{x}=0.075$ composition prepared by solid state reaction and sol-gel route are shown in Fig. 6. Smooth surface and uniform distribution of grain are observed for composition synthesized by solid state reaction (Fig. 6 a).
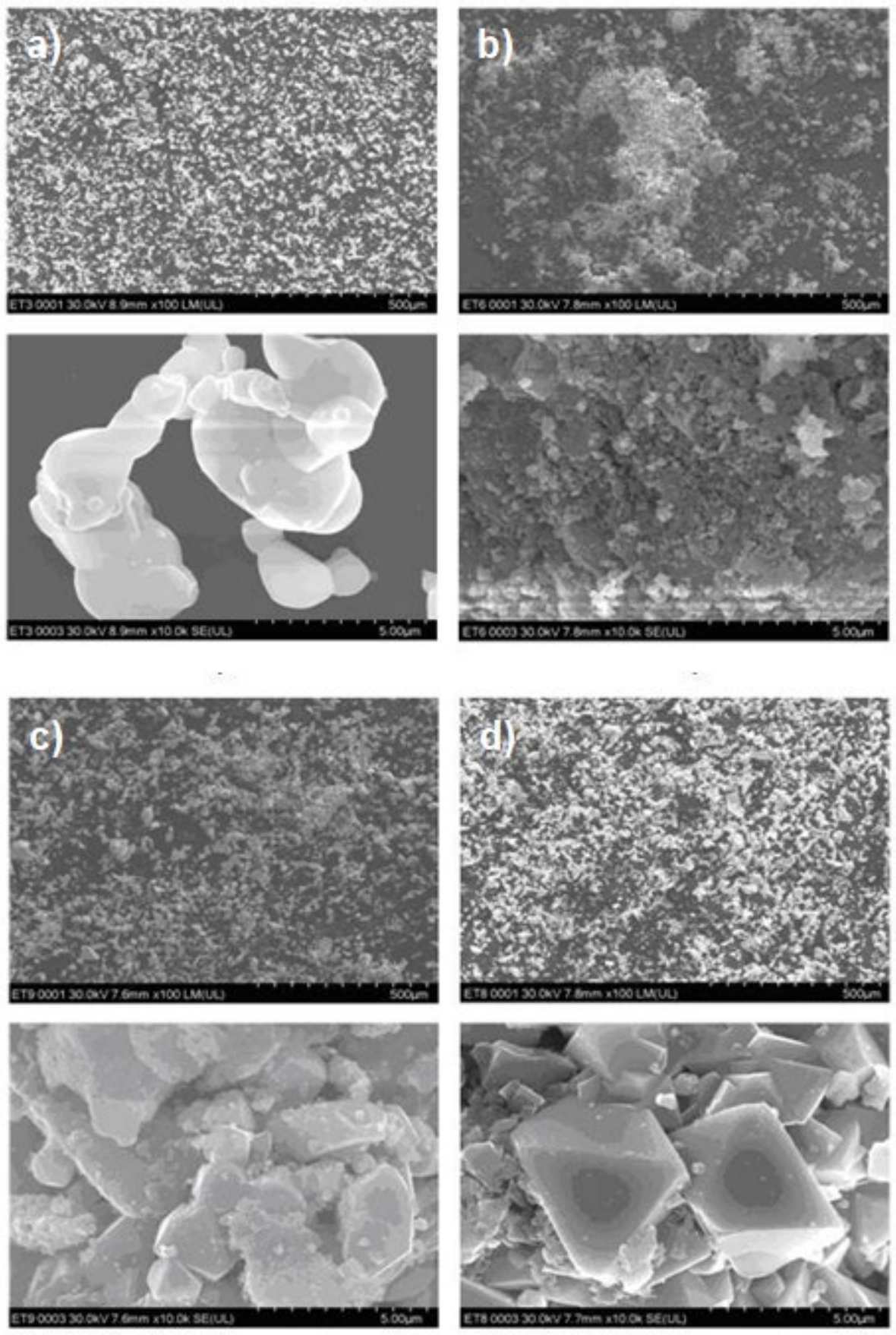

Fig. 6. SEM images at $\mathrm{x} 100$ (up) and $\mathrm{x} 10.0 \mathrm{k}$ (down) magnification of $\mathrm{x}=0.075$ composition prepared by solid state reaction (a) and sol-gel method using (b) isopropyl alcohol, (c) sucrose or (d) ethylene glycol. 
Particles with an angular shape are observed for the sol-gel synthesized samples using sucrose or ethylene glycol, as seen in Fig. 6c and 6d. The micrographs of zirconium indium oxide prepared by sol-gel with isopropyl alcohol as solvent (Fig. 6b) showed agglomeration of the particles. In all the cases the size of grains is situated in the micrometer range.

\section{Conclusions}

Structural evolution of the bulk materials in the candidate TCOs zirconium-doped indium oxide prepared by solid state reaction at high temperature and the sol-gel method were investigated. XRPD analysis shows that cubic bixbyite structure was confirmed with pure phases obtained in all the prepared samples. Measured diffuse reflectance spectra (DRS) show a decrease of max. \%R for compositions prepared by the sol-gel method; moreover the sucrose addition as polymerization agent improve the optical properties. The surface morphology of the all prepared samples appears homogeneous and consists of small grains with size ranges in the micrometer domain.

\section{References}

[1] D. S. Ginley, H. Hosono, D. C. Paine, “Handbook of Transparent Conductors”, Springer, Berlin, 2010.

[2] J. Xu, Y. Chen, Y, J. Shen, Ethanol sensor based on hexagonal indium oxide nanorods prepared by solvothermal methods, Mater. Lett. (2008), 1363-1365. https://doi.org/10.1016/j.matlet.2007.08.054

[3] S.M. Rozati, S. Mirzapour, M. G. Takwale, B. R. Marathe and V. G. Bhide, Influence of annealing on evaporated indium oxide thin films, Mater. Chem. Phys. 36 (1994) 252-255. https://doi.org/10.1016/0254-0584(94)90038-8

[4] Z. Yuan, X. Zhu, X. Wang, X. Cai, B. Zhang, D. Qiu, H. Wu, Annealing effects of $\operatorname{In}_{2} \mathrm{O}_{3}$ thin films on electrical properties and application in thin film transistors, Thin Solid Films, 519 (2011) 3254-3258. https://doi.org/10.1016/j.tsf.2010.12.022

[5] R.K. Gupta, N. Mamidi, K. Ghosh, S.R. Mishra, P.K. Kahol, Growth and characterization of $\mathrm{In}_{2} \mathrm{O}_{3}$ thin films prepared by pulsed laser deposition, J. Optoelectron. Adv. Mater., 7 (2007) 2211-2216.

[6] M. Girtan , G. Folcher, Structural and optical properties of indium oxide thin films prepared by an ultrasonic spray CVD process, Surf. Coat. Technol. 172 (2003) 242-250. https://doi.org/10.1016/S0257-8972(03)00334-7

[7] J. Joseph Prince, S. Ramamurthy, B. Subramanian, C. Sanjeeviraja, M. Jayachandran, Spray pyrolysis growth and material properties of In2O3 films, J. Cryst. Growth, 240 (2002) 142151. https://doi.org/10.1016/S0022-0248(01)02161-3

[8] S. Jana, P. K. Biswas, Effect of Zr (IV) doping on the optical properties of sol-gel based nanostructured indium oxide films on glass, Mater. Chem. Phys., 117 (2009) 511-516. https://doi.org/10.1016/j.matchemphys.2009.06.038

[9] S. B. Qadri, H. Kim, H. R. Khan, A. Pique, J. S. Horwitz, D. Chrisey, W. J. Kim, E. F. Skelton, Transparent conducting films of $\mathrm{In}_{2} \mathrm{O}_{3}-\mathrm{ZrO}_{2}, \mathrm{SnO}_{2}-\mathrm{ZrO}_{2}$ and $\mathrm{ZnO}-\mathrm{ZrO}_{2}$, Thin Solid Films 377-378 (2000) 750-754. https://doi.org/10.1016/S0040-6090(00)01328-6

[10] Y.C. Liang, Surface morphology and conductivity of zirconium-doped nanostructured indium oxide films with various crystallographic features, Ceram. Int. 36 (2010) 1743-1747. https://doi.org/10.1016/j.ceramint.2010.03.004 